\title{
Regenerative frontiers in craniofacial reconstruction: grand challenges and opportunities for the mammalian transforming growth factor- $\beta$ proteins
}

\author{
Ugo Ripamonti* and Roland Manfred Klar \\ Bone Research Unit, Medical Research Council/University of the Witwatersrand, Johannesburg, South Africa
}

Edited by:

Vesa Kaartinen, University of Michigan, USA

Reviewed by:

Yuji Mishina, University of Michigan, USA

Michael Cunningham, University of Washington, USA

*Correspondence:

Ugo Ripamonti, Bone Research Unit,

Medical Research Council/University of

the Witwatersrand, 7 York Road,

Johannesburg, South Africa.

e-mail: ugo.ripamonti@wits.ac.za
Science's fascination with bone and its repair processes span for thousands of years since the ancient Greek Hippocrates, the father of Medicine, made the key discovery that bone heals without scarring. Through the centuries, several lucid investigators perceived that the extracellular matrix of bone must be a reservoir of differentiating and morphogenetic factors ultimately responsible for its pronounced healing potential (reviewed in Urist, 1968, 1994; Reddi, 2000; Ripamonti et al., 2006).

Keywords: regenerative medicine, osteogenic proteins, transforming growth factor- $\beta$ proteins, bone morphogenetic proteins

\section{HISTORICAL PERSPECTIVE}

Restoring anatomical function of complex disfiguring craniofacial defects and anomalies remains a grand unsolved challenge. Those of us who have not suffered the outrage of facial deformity visited upon patients either as a developmental misfortune or the scourge of disease or violence can only imagine the effects thereof. Loss of facial features not only denies patients the most basic human functions but also rob them of a sense of identity with all the associated mental anguish.

Bone has fascinated a plethora of scientists throughout the world since the bone matrix is in both soluble and insoluble states (Reddi, 1997); in his classic Cell's contribution, Reddi states that there is a continuum between the soluble and insoluble states of the bone matrix that is regulated by signals in solution interacting with the insoluble signals of the extracellular matrix (Reddi, 1997).

The bone and the skeleton evolved for several purposes, primarily for the emergence of the vertebrates, body erection and locomotion, copulation, for protection of the brain, the spinal cord and the hematopoietic marrow and as reservoir of vital ions such as calcium, phosphate, magnesium and zinc (Reddi, 1997). Body erection freed the upper limbs for superior foraging and more industrious Homo-like activities including the use of tools for hunting, foraging above all, however, for maternal care, contributing thus to the speciation of the genus Homo ultimately directing the emergence of the Homo clade.

What it is that confers to the skeleton and its bones this remarkable repair potential known since Hippocratic times? Importantly, normal and pathologic bone modeling and remodeling are inexorably tied to angiogenesis (Saadeh et al., 1999). Angiogenesis is a prerequisite for osteogenesis (Trueta, 1963). In his studies, Trueta presented the critical role of the vessels in osteogenesis and defined the "osteogenetic vessel" as critically important differentiating vessels having a profound osteogenic function (Trueta, 1963).
Trueta also referred to von Haller (1763) who has hypothesized that the vascular system is responsible for osteogenesis (Trueta, 1963). Later, during last century, Keith (1927) has suggested that "bone-forming cells are derived from the endothelium of invading capillaries." The possibility that bone-forming cells, or osteoblasts, are derived from the endothelium is morphologically presented in Figure 1A; endothelial-like cells are shown to migrate from the vascular compartment to the osteoblastic/bone-forming compartment actively secreting the newly formed bone matrix (Figure 1A). Long before von Haller, Keith, and Trueta, the multifaceted eclectic personality of Aristotle as quoted by Lanza and Vegetti (1971) and Crivellato et al. (2007) credited the sprouting blood vessels with a patterning function during organogenesis. Figure 1A also shows morphologically the plasticity of the migrating endothelial cells and the superbly intimate relationships of the endothelium and its basement membrane with the secreting osteoblastic-like cells.

Majestically, Aristotle credited the sprouting capillaries with patterning functions during organogenesis and that the architectural patterning of vessel growth functions as a "frame" or "model" to shape the body structure. The Aristotelian scenario of patterning organogenetic capillaries is highlighted in Figures 1B-D.; the sprouting capillaries are soon surrounded by mesenchymal cellular condensations progressively closing around the invading capillaries (Figure 1C); the vessels are thus "morphogenetic" since initiate the morphogenesis of cellular condensations, i.e., it is the vessel that sets into motion the ripple-like cascade of tissue condensations thus providing cellular elements for cross-talking at cellular and transmembrane receptor levels with both the endothelial and pericytic paravascular cells of the "morphogenetic" and "osteogenetic" vessels of Aristotle's and Trueta's definitions (Figures 1B-D) (Trueta, 1963). This Aristotelian patterning scenario of sequential inductive and differentiating cascades of molecular and cellular 

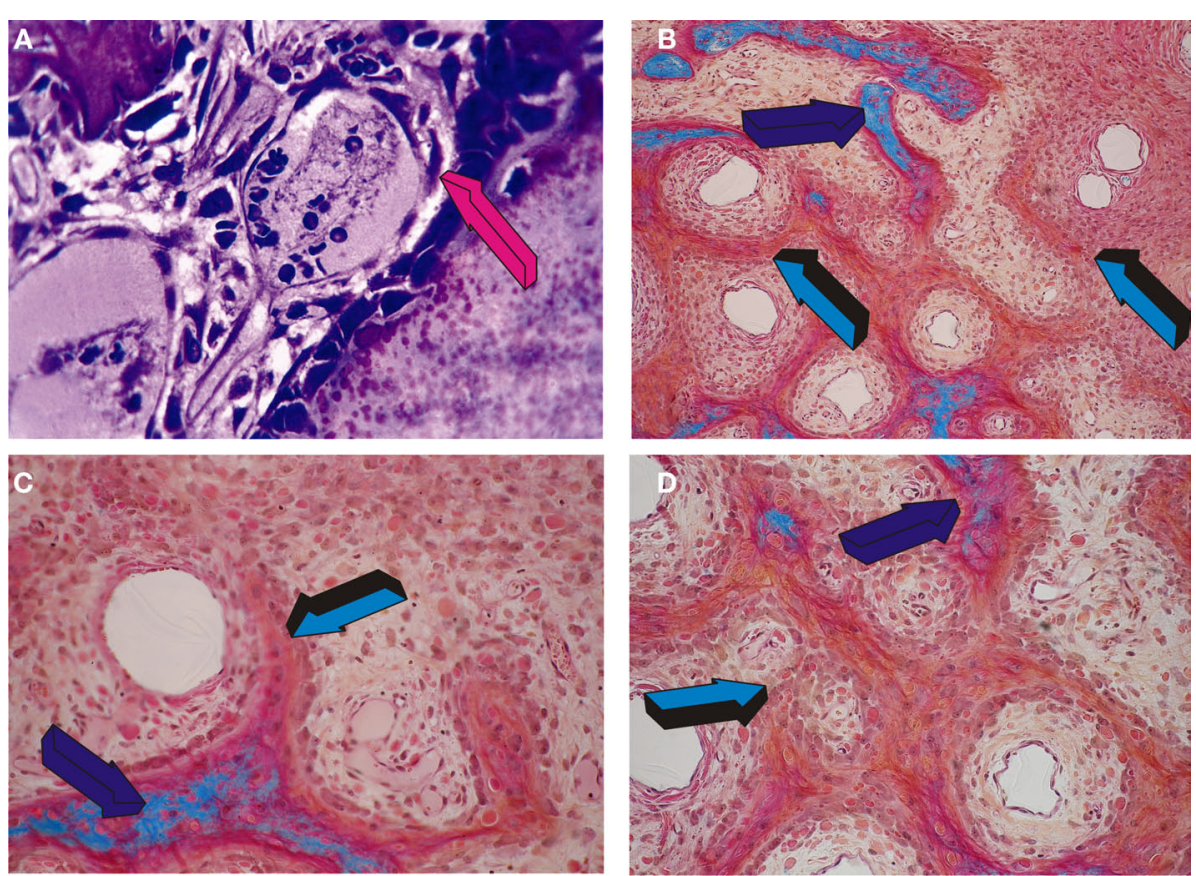

FIGURE 1 |Angiogenesis, capillary sprouting, vascular invasion, cellular trafficking, cell differentiation and the induction of the primate corticocancellous osteonic bone. (A) Endothelial-like cell detachment and migration from the vascular compartment (magenta arrow) to the bone-forming osteogenetic compartment (top right of magenta arrow); (B-D) osteogenesis in angiogenesis in the non-human primate Papio ursinus. Capillary sprouting and invasion patterning the induction of mesenchymal cellular condensations around the "osteogenetic vessels" of Trueta's definition (Trueta, 1963); (B) Mesenchymal condensations (light blue arrow) patterned around the invading osteogenetic vessels with foci of mineralization (dark blue arrow) facing osteoid seems populated by differentiating osteoblast-like cells; (C,D) Tissue patterning and morphogenesis as induced by the osteogenetic vessels with newly forming mesenchymal condensations patterning around the central morphogenetic vessels (light blue arrow in $\mathrm{C}$ and D) with foci of mineralization of the newly formed bone (dark blue arrows). events is cathartically condensed and summarized by the fascinating scenario of "bone: formation by autoinduction" (Urist, 1965; Reddi and Huggins, 1972).

\section{BONE: FORMATION BY AUTOINDUCTION}

The history and chronicle of the scientific discoveries on the healing potential of bone is rich with significant advances that have repeatedly shaped our understanding of bone tissue engineering and regeneration. Due to constraints of space, the interested reader is encouraged to read the path of discoveries that have characterized the evolution of bone tissue engineering (Urist, 1994; Reddi, 2000; Ripamonti et al., 2006).

Seminal research work has been published by several scientists around the globe though it is difficult to chart a non-opinionated historical perspective on the studies of bone regeneration. We will enjoy, however, following a trial of references back through the centuries at least recognizing some landmark discoveries and developments.

Senn (1889) implanted decalcified antiseptic bone to treat skull defects in a canine model; in his futuristic classic work, Senn demonstrated the value of implanting disks or plates of decalcified bone in canine calvarial defects. Astutely, Senn noticed that the implanted decalcified matrix was incorporated by a large mass of embryonic tissue, a condition he has stated, favorable to the formation of new bone at the site of implantation of decalcified bone (Senn, 1889).
Senn two centuries ago lucidly saw that postnatal bone regeneration after implantation of decalcified bone matrix develops via embryonic tissue formation.

Trueta's (1963) morphologically superb studies on the influence of angiogenesis in osteogenesis have seeded several areas of research interest as well as providing an opinion paper on the critical role of the vessels in osteogenesis. Levander and collaborators provided a series of investigations reporting the heterotopic intramuscular induction of bone formation by ethanol-treated and partially extracted bone matrices (Levander, 1938). It is our opinion that in spite of the grand published research work, Levander did not reach the deserved fame simply by failing to provide a name for the hypothesized "substance with bone-forming properties" (Levander, 1938; Levander and Willestaedt, 1946). Levander stated that heterotopic intramuscular formation of bone is induced by "some substance extracted by alcohol from the skeletal tissue, a substance having the power to activate the non-specific mesenchymal tissue into the formation of bone tissue, either directly or via the embryonic prenatal stage of bone, viz. cartilage" (Levander, 1938; Levander and Willestaedt, 1946).

Levander (Levander, 1938; Levander and Willestaedt, 1946) clearly identified that the induction of bone formation in postnatal life recapitulates events that occur in the normal course of embryonic development (Levander, 1938). Levander (1945) went 
further by introducing the term "tissue induction" by this as yet unknown substance he has hypothesized to be present within the bone matrix.

Years later Lacroix (1945) has had the vision to at least propose a short concise term for this morphogenetic still unknown factor. Lacroix (1945) has named this osteogenic substance within the bone matrix or, prophetically, a group of substances with bone-forming properties, as “osteogenins.” Of note, Lacroix letter to Nature depreciated all the hard work of the Swedes, for at least 10 years before Lacroix' letter, Levander and co-workers have unequivocally demonstrated the induction of bone formation using alcoholic extracts of bone matrix (M. R. Urist, personal communication; Levander, 1938, 1945; Levander and Willestaedt, 1946).

We are of the opinion that also Moss (1958) significantly contributed by reporting in Science on the "extraction of an osteogenic inductor from bone." The seminal work of Urist (1965), adding to the previously published experimental work of Levander, Lacroix, Moss and borrowing the term induction from Spemann (1938) and Levander (1945), provided the reproducible evidence that heterotopic intramuscular implantation of allogeneic demineralized bone matrix in rodents, lagomorphs and into a variety of orthotopic bony defects in humans results in the induction of bone formation (Urist, 1965). His visionary work on "bone: formation by autoinduction" has been immortalized by his classic 1965 Science's paper (Urist, 1965). The important vision of Urist was the introduction of the morphogenetic concept of a hypothetical bone morphogenetic protein complex within the bone matrix that would initiate the genesis of form and function, i.e., bone morphogenesis. Because of his continuous studies on the induction of bone formation in a variety of animal models including humans but particularly in our opinion for the selection of the ideal term "bone morphogenetic protein" (Urist and Strates, 1971) he has claimed the fame to be the initiator of the "bone induction principle," a term Urist himself has set in the sixties (Urist et al., 1967, 1968).

Reddi and his team excelled by thoroughly investigating the biochemical and morphological cascades of bone differentiation by induction (Reddi and Huggins, 1972; Reddi, 1984) and venturing into partial purification of these still "elusive" morphogenetic factors (Sampath and Reddi, 1981, 1983; Sampath et al., 1987).

Important studies showed that osteogenesis is also induced by transplantation of the urinary bladder, ligation of the renal arteries, or surgical lesions of the wall of the urinary bladder. Huggins (1968) and Friedenstein (1968) excelled in their own right by publishing classic papers on the fascinating phenomenon of uroepithelial osteogenesis. Friedenstein ultimately asked the compelling question that eventually has defined the "bone induction principle" and the "osteogenic activity" of several transplanted matrices, including bone, dentine, and uroepithelium. How is the inductive influence of the transitional epithelium and other matrices including demineralized bone and dentine transferred to the competent responding cells? Friedenstein's elegant research on transfilter bone induction naturally implied the presence of a soluble "inductor," i.e., a diffusible soluble molecular signal ultimately responsible for the induction of bone formation (Friedenstein, 1962).

The grand work of Urist and Reddi provided the reproducible evidence of the osteogenic activity of demineralized bone and dentine matrices implying the presence of morphogenetic factors and, as per Urist speculation, of a bone morphogenetic protein complex within the bone matrix (Urist and Strates, 1971). The identification of this elusive bone morphogenetic protein complex has been hindered by the fact that the extracellular matrix of bone exists in the solid state (Reddi, 1997) and by the limited quantities of putative morphogenetic proteins within the extracellular matrix of bone tightly bound to the organic and inorganic components of the bone matrix (Sampath and Reddi, 1984).

Fundamental steps forward were the studies by Reddi and Sampath who identified the elusive proteins to be part of the extracellular matrix of bone. The bone matrix in the solid state was demineralized to show the endochondral osteoinductivity of the crude bone matrix preparations (Reddi and Huggins, 1972; Sampath and Reddi, 1981; Reddi, 1984); the demineralized bone matrix was then dissociatively extracted with chaotropic agents such as guanidinium hydrochloride and/or urea; the extracted intact bone matrix yielded a soluble signal, i.e., the proteinaceous component, and an insoluble signal or substratum, i.e., mainly insoluble collagenous bone matrix, inactive after the extraction of the osteogenic proteins (Sampath and Reddi, 1981); both signals, when singly implanted subcutaneously in the rodent bioassay, were inactive (Sampath and Reddi, 1981). This implied that the osteogenic activity of the intact demineralized bone matrix was lost after the dissociative extraction of the matrix components (Sampath and Reddi, 1981).

The realization that the bone matrix could be dissociatively extracted and that the extracted components could be recombined, more figuratively reconstituted with the insoluble collagenous component or residue restoring the biological activity of the crude but intact demineralized bone matrix preparations, showed unequivocally that the extracellular matrix of bone is a reservoir of morphogenetic soluble signals that per se initiate the cascade of bone differentiation by induction (Sampath and Reddi, 1981, 1983; Ripamonti and Reddi, 1995; Reddi, 2000). Additionally and importantly, the classic studies of Sampath and Reddi showed that the soluble signals need to be reconstituted with an insoluble signal or substratum to trigger the ripple-like cascade of bone differentiation by induction (Sampath and Reddi, 1981, 1983; Reddi, 2000). The operational reconstitution of the soluble signals with an insoluble signal or substratum (Sampath and Reddi, 1981, 1983; Ripamonti and Reddi, 1995) was a key experiment that propelled the bone induction principle into the pre-clinical and clinical arenas providing a bona fide bioassay for putative osteogenic proteins (Sampath and Reddi, 1981, 1983; Ripamonti and Reddi, 1995; Reddi, 2000).

The experimental work of Reddi's group established what it is now known as the tissue engineering paradigm whereby soluble molecular signals are recombined with insoluble signals or substrata to trigger the ripple-like cascade of bone differentiation by induction (Sampath and Reddi, 1981, 1983; Khouri et al., 1991; Reddi, 2000). Importantly, restoration of the biological activity of osteogenic proteins in the rat subcutaneous bioassay was also possible by reconstituting xenogeneic homologous proteins providing that the solubilized proteins are reconstituted with the recipient rodent allogeneic insoluble collagenous matrix (Sampath and Reddi, 1983). This implied that there are homologous inductive proteins across mammalian species whereas the insoluble collagenous bone matrix retains the antigenic load and that the initiation 
of bone formation is only triggered when using allogeneic but not xenogeneic collagenous bone matrix preparations (Sampath and Reddi, 1983; Ripamonti and Reddi, 1995).

The realization that the putative and elusive osteoinductive proteins were tightly bound to the bone matrix and could be dissociatively extracted and reconstituted with an insoluble signal or substratum, set into motion the race for the purification of the osteogenic proteins which culminated in the isolation, sequencing and cloning of an entirely new family of protein initiators collectively called the bone morphogenetic/osteogenic proteins (BMPs/OPs); BMPs/OPs belong to the transforming growth factor- $\beta$ (TGF- $\beta$ ) supergene family (Wozney et al., 1988; Özkaynak et al., 1990; Reddi, 2000; Ripamonti et al., 2004; Ripamonti, 2006a). Molecular cloning of the now available recombinant human proteins, i.e., BMP-2 and BMP-7, the latter also known as osteogenic protein-1 (OP-1), has allowed extensive testing in pre-clinical and clinical contexts, from laboratory benches to non-human and human primates (Reddi, 2000; Ripamonti et al., 2000, 2007; Friedlander et al., 2001; Govender et al., 2002; Ripamonti, 2006a, 2010).

\section{REDUNDANCY: MULTIPLE MOLECULAR SIGNALS INITIATING THE INDUCTION OF BONE FORMATION}

Bone tissue engineering in clinical contexts has proven however to be an elusive target when compared to results obtained in preclinical studies including non-human primate species (Ripamonti et al., 2007). The induction of bone formation by recombinant hBMPs/OPs has dramatically shown that regenerative medicine in clinical contexts is on a different scale altogether when compared to animal models that may not adequately translate and reproduce morphogens-related therapeutic responses in Homo sapiens yielding uninspiring amounts of newly induced bone often comparatively lower than autogenous bone grafts (Garrison et al., 2007; Gautschi et al., 2007; Ripamonti et al., 2007).

Importantly, implantation of recombinant hOP-1 in the nonhuman primate Papio ursinus resulted in the expression of OP-1, BMP- 3 and TGF- $\beta_{1}$ mRNAs as evaluated by Northern blot analyses (Ripamonti, 2005). The reported data showed a temporal and spatial pattern of gene expression which has indicated progressing stages of osteogenic differentiation during the initiation of bone formation by increasing doses of the hOP-1 osteogenic device (Ripamonti, 2005). It was noteworthy that there was a temporal and spatial expression pattern of TGF- $\beta_{1}$ mRNAs with a relatively high expression on day 30 when compared to low expression patterns on day 15 and 90 indicating the presence of a specific temporal window during which expression of TGF- $\beta$, mRNA is mandatory for optimal osteogenesis (Ripamonti, 2005).

The importance of the TGF- $\beta$ proteins has been dramatically shown by the synergistic interaction with hOP-1 to induce massive heterotopic and orthotopic ossicles in the non-human primate P. ursinus (Ripamonti et al., 1997; Duneas et al., 1998); surprisingly and in marked contrast to other animal models, it was also found that recombinant or platelet-derived TGF- $\beta_{1}$ induce endochondral bone differentiation when singly implanted in heterotopic intramuscular sites of $P$. ursinus (Ripamonti et al., 1997; Duneas et al., 1998). The above discoveries casted additional and important unexpected functions to the TGF- $\beta_{1}$ protein in primates (Ripamonti et al., 1997). Indeed, TGF- $\beta_{1}$ implantation in heterotopic sites of rodents, lagomorphs and canine models does not induce endochondral bone differentiation but rather a pronounced fibrogenic response without any evidence of bone formation (Roberts et al., 1986).

In recent years, several different studies have cast a new light on the specific role of TGF- $\beta$ isoforms within the bone matrix. Balooch et al. showed that TGF- $\beta$ regulates the mechanical properties and composition of the bone matrix. There is also a direct relationship between the regulation of gene expression by TGF- $\beta$ and the mechanical properties of the bone matrix of endochondral or intramembranous origin (Balooch et al., 2005). Similarly, mRNA expression of TGF- $\beta$ gene products is essential for joint morphogenesis (Spagnoli et al., 2007). Joint morphogenesis with regeneration of the entire articular surface of the rabbit synovial joint has been recently shown after cell recruitment and "homing" initiated by the hTGF- $\beta_{3}$ isoform (Lee et al., 2010). We have also learned that the mammalian TGF- $\beta$ isoforms are critical for the control and initiation of angiogenesis by modulating the expression of vascular endothelial growth factor by osteoblasts and osteoblastic-like cells (Saadeh et al., 1999).

Systematic studies in the non-human primate $P$. ursinus have shown a previously unknown function of the mammalian TGF- $\beta$ isoforms, i.e., the induction of endochondral bone formation, defined as the de novo generation of endochondral bone in heterotopic, intramuscular sites (Ripamonti et al., 1997, 2000, 2008; Ripamonti and Roden, 2010). This is in marked contrast to studies in rodents and lagomorphs where only fibrogenic effects are observed (Roberts et al., 1986). Our studies on the presence of multiple forms of osteogenic proteins of the TGF- $\beta$ superfamily have confirmed that homologous but molecularly different protein isoforms of the TGF- $\beta$ supergene family, conserved in structure but diverse in ligand recognition (Sun, 2003), control tissue induction and morphogenesis of endochondral bone formation (Ripamonti et al., 1997, 2000, 2008; Ripamonti and Roden, 2010).

Heterotopic intramuscular implantation of doses of hTGF- $\beta_{3}$ in $P$. ursinus results in the rapid induction of large and corticalized ossicles by day 30 and 90 after implantation (Figure 2). Hyper cellular osteoblastic activity, osteoid synthesis, angiogenesis and prominent capillary sprouting have suggested a novel molecular and morphological basis for the induction of bone formation in clinical contexts (Ripamonti et al., 2008). Our laboratories have also shown substantial induction of bone formation with mineralization of the newly formed bone as early as 30 days after implantation in non-healing full thickness mandibular defects of P. ursinus (Ripamonti, 2006b, The Marshall Urist Awarded Lecture), confirming that the hTGF- $\beta_{3}$ isoform is the most powerful osteoinductive morphogen so far tested in non-human primates of the species $P$. ursinus (Ripamonti et al., 2008; Ripamonti, 2010).

\section{CHALLENGES AND OPPORTUNITIES FOR THE} TGF- $\beta_{3}-$ OSTEOGENIC DEVICE

The greatest challenge of regenerative medicine and bone tissue engineering is to translate in clinical contexts what has been so dramatically discovered in pre-clinical animal models as well as on the laboratory bench (Reddi, 2000; Ripamonti et al., 2007). Reconstruction of large craniofacial defects in humans requires the harvesting of autogenous bone grafts from a distant donor site 


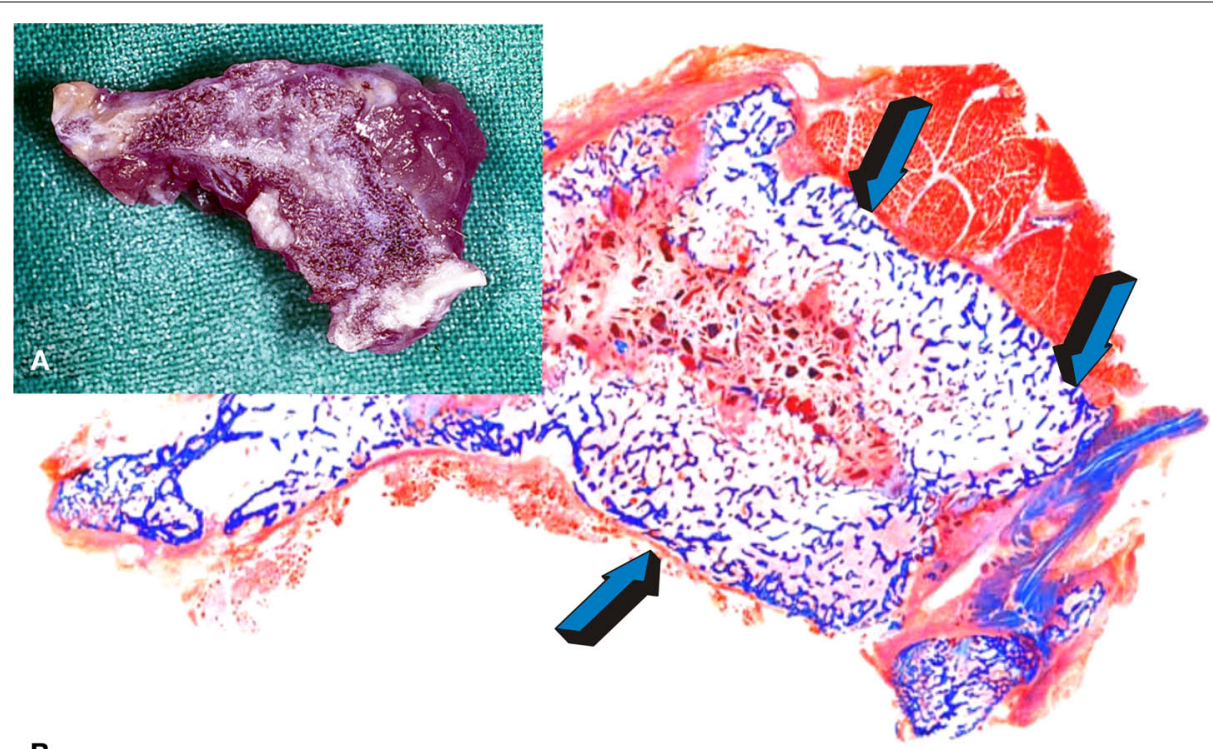

B

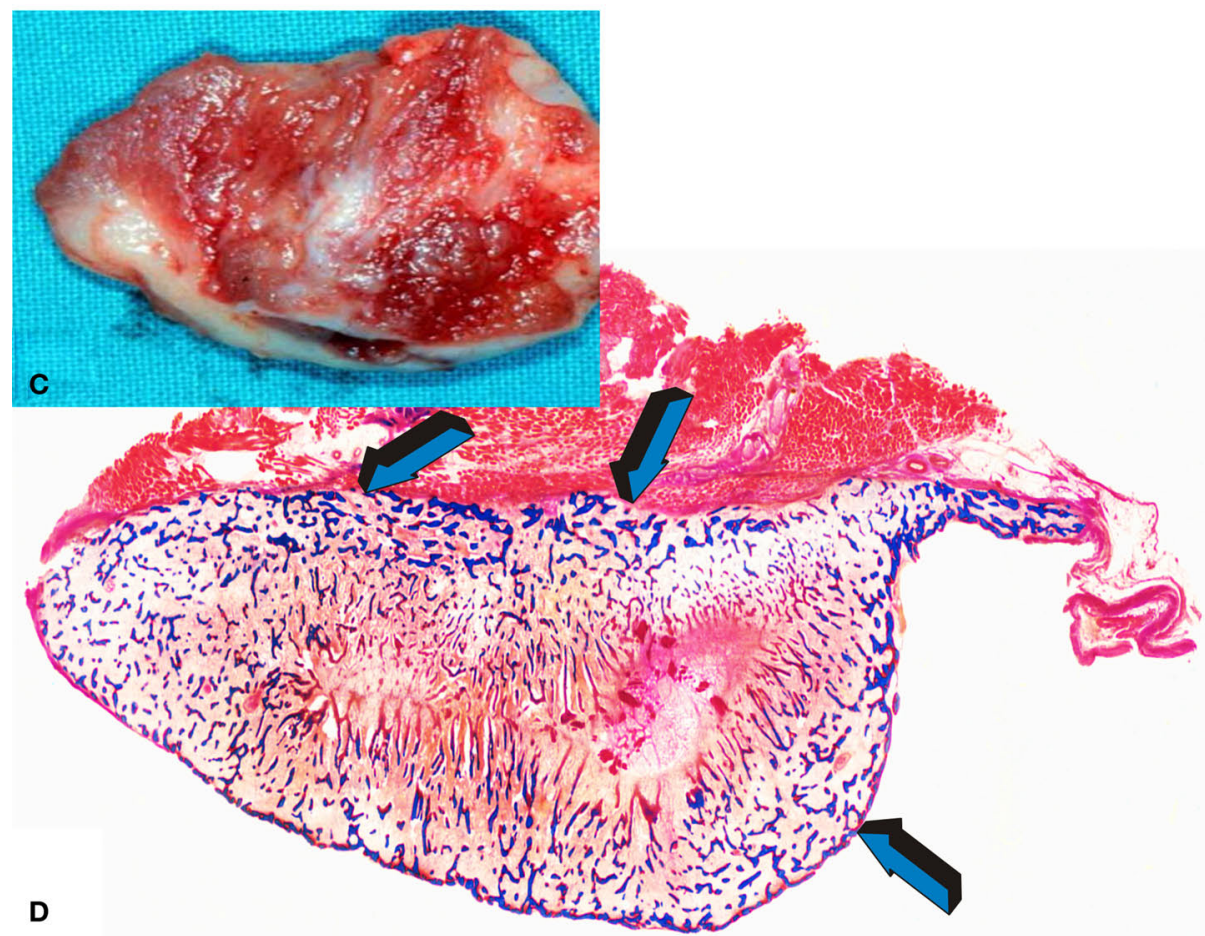

FIGURE 2 | Tissue induction and morphogenesis of large and corticalized ossicles $(\mathbf{A}, \mathbf{C})$ upon implantation of $125 \mu \mathrm{g} \mathrm{hTGF}-\boldsymbol{\beta}_{3}$ in the Rectus Abdominis muscles of adult baboons Papio ursinus harvested on day 90 after heterotopic implantation; (B,D) undecalcified low power view of the newly formed ossicles with mineralized bone (in blue) with peripheral corticalization (light blue arrows) enveloping mineralized bone covered by osteoid seams and scattered remnants of collagenous matrix as carrier. most often the iliac crest with associated harvest-related morbidity. Additional limitations are the finite volume of available bone from donor sites and adapting the donor bone to fit the shape of the recipient defect, the final challenge to autogenous bone grafting in clinical contexts (Ripamonti et al., 2008).

The reported above studies have provided a fascinating scenario of "the bone induction principle" (Urist et al., 1967, 1968). Whilst it may be construed to be presumptuous to predict the future of bone tissue engineering in clinical contexts, we nevertheless would like to venture to list the grand opportunities and challenges ahead of the hTGF- $\beta_{3}$ /osteogenic devices for skeletal reconstruction in clinical contexts.

The mammalian TGF- $\beta$ isoforms may regulate the expression of the homologous but molecularly different BMPs/OPs, which initiate the induction of bone formation. The TGF- $\beta$ proteins may act upstream to the BMPs/OPs and may induce the induction of 
heterotopic bone by expressing selected BMPs/OPs gene products ultimately resulting in the induction of bone formation. Current and previous studies have shown the expression of BMP-3 and OP-1 mRNAs as evaluated by Northern blotting (Duneas et al., 1998; Ripamonti et al., 2000; Ripamonti and Roden, 2010) and RT-PCR analyses (Ripamonti et al., 2008). We have also shown that when OP- 1 transcription increases, TGF- $\beta_{3}$ increases exponentially and always remains at a higher level than OP-1 expression even in extracted macroporous constructs pre-treated with hOP-1 (Ripamonti et al., 2010; Ripamonti and Klar, 2010). The grand challenges and opportunities for craniofacial and skeletal reconstructionists, tissue engineers and molecular biologists alike is to now design therapeutic strategies deploying hTGF- $\beta_{3} /$ based osteogenic devices in clinical contexts for regeneration of human skeletal defects.

The complex signaling patterning controlling bone development in both embryonic development and postnatal tissue induction and morphogenesis are still long standing scientific problems and thus the focus of great curiosity to dissect embryonic development and tissue patterning during regenerative medicine; we are of the opinion that the hTGF- $\beta_{3} /$ osteogenic device may shed further mechanistic and therapeutic insights into "bone: formation by autoinduction" (Urist, 1965).

\section{REFERENCES}

Balooch, G., Balooch, M., Nalla, R. K., Schilling, S., Filvaroff, E. H., Marshall, G. W., Marshall, S. J., Ritchie, R. O., Derynck, R., and Alliston, T. (2005). Tgf-beta regulates the mechanical properties and composition of bone matrix. Proc. Natl. Acad. Sci. U.S.A. 102, 18813-18818.

Crivellato, E., Nico, B., and Ribatti, D. (2007). Contribution of endothelial cells to organogenesis: a modern reappraisal of an old aristotelian concept. J. Anat. 211, 415-427.

Duneas, N., Crooks, J., and Ripamonti, U. (1998). Transforming growth factorbeta 1: induction of bone morphogenetic protein genes expression during endochondral bone formation in the baboon, and synergistic interaction with osteogenic protein-1 (BMP-7). Growth Factors 15, 259-277.

Friedenstein, A. J. (1962). Humoral nature of osteogenic activity of transitional epithelium. Nature 194, 698-699.

Friedenstein, A. Y. (1968). Induction of bone tissue by transitional epithelium. Clin. Orthop. Relat. Res. 59, 21-37.

Friedlaender, G. E., Perry, C. R., Cole, J.D., Cook, S. D., Cierny, G., Muschler, G. F., Zych, G. A., Calhoun, J. H., LaForte, A. J., and Yin, S. (2001). Osteogenic protein-1 (bone morphogenetic protein-7) in the treatment of tibial nonunions. J. Bone Joint Surg. Am. 83A, S151-S158.

Garrison, K. R., Donell, S., Ryder, J., Shemilt, I.,Mugford, M.,Harvey, I.,

Finally, we have seen that animal models including nonhuman primates may not adequately translate and reproduce morphogens-related therapeutic responses in $\mathrm{H}$. sapiens. It is our opinion that bone tissue engineering and regenerative medicine at large need now to start to systematically identify the molecular and cellular basis responsible for the differences in healing patterns amongst mammals. The concerted genetic and tissue biology approaches will break the boundaries of super healing (Ripamonti, 2010).

\section{ACKNOWLEDGMENTS}

The reported research work against the dogma on the endochondral osteoinductivity of the non-canonical transforming growth factor- $\beta$ isoforms has been constantly supported by the Medical Research Council, the University of the Witwatersrand, Johannesburg, and the National Research Foundation of South Africa. The authors acknowledge the constructive and unique work of a series of technologists and scientists who have worked at the Bone Research Laboratory, in particular Barbara van den Heever, June Teare, Ruqayya Parak, Louise Renton, Laura Yates, Manolis Heliotis, and Carlo Ferretti. We thank Professors Urist and Reddi for inspirational scientific insights into "bone: formation by autoinduction."

epithelium of the urinary tract. Clin. Orthop. Relat. Res. 59, 7-19.

Keith, A. (1927). Concerning the origin and nature of osteoblasts. Proc. R. Soc. Med. 21, 301-308.

Khouri, R. K., Koudsi, B., and Reddi, H. (1991). Tissue transformation into bone in vivo. A potential practical application. ., Am. Med. Assoc. 266, 1953-1955.

Lacroix, P. (1945). Recent investigations on the growth of bone. Nature 156, 576.

Lanza, D., and Vegetti, M. (1971). Opere biologiche di Aristotele. A cura di Diego Lanza e Mario Vegetti. Torino: UTET.

Lee, C. H., Cook, J. L., Mendelson, A., Moioli, E. K., Yao, H., and Mao, J. J. (2010). Regeneration of the articular surface of the rabbit synovial joint by cell homing: a proof of concept study. The Lancet 376, 440-448.

Levander, G. (1938). A study of bone regeneration. Surg. Gynecol. Obste. 67, 705-714.

Levander, G. (1945). Tissue induction. Nature 155, 148-149.

Levander, G., and Willestaedt, H. (1946). Alcohol-soluble osteogenetic substance from bone marrow. Nature 3992, 587.

Moss, M. L. (1958). Extraction of an osteogenic inductor factor from bone. Science 127, 755-756.

Özkaynak, E., Rueger, D. C., Drier, E. A. Corbett, C., Ridge, R. J., Sampath, T. K., and Oppermann, H. (1990).
OP-1 cDNA encodes an osteogenic protein in the TGF- $\beta$ family. EMBO J. 9, 2085-2093.

Reddi,A.H. (1984). “Extracellular matrix and development," in Extracellular Matrix Biochemistry, eds K. A. Piez, and A. H. Reddi (New York: Elsevier), 375-412.

Reddi,A.H. (1997). Bone morphogenesis and modeling: soluble signals sculpt osteosomes in the solid state. Cell 89, 159-161.

Reddi, A. H. (2000). Role of bone morphogenetic proteins in skeletal tissue engineering of bone and cartilage: inductive signals, stem cells, and biomimetic biomaterials. Tissue Eng. 6, 351-359.

Reddi, A. H., and Huggins, C. B. (1972). Biochemical sequences in the transformation of normal fibroblast in adolescent rats. Proc. Natl. Acad. Sci. U.S.A. 69, 1601-1605.

Ripamonti, U. (2005). Bone induction by recombinant human osteogenic protein-1 (hOP-1, BMP-7) in the primate Papio ursinus with expression of mRNA of gene products of the TGF- $\beta$ superfamily. J. Cell. Mol. Med. 9, 911-928.

Ripamonti, U.(2006a). Soluble osteogenic molecular signals and the induction of bone formation. Biomaterials 27, 807-822.

Ripamonti, U. (2006b). “The Marshall Urist awarded lecture - bone: formation by autoinduction," in Proceedings of the 6th International Conference 
on Bone Morphogenetic Proteins, eds S. Vukicevic and A. H. Reddi, (Dubrovnik: Depol Org.), 1.

Ripamonti, U. (2010). Soluble and insoluble signals sculpt osteogenesis in angiogenesis. World J. Biol. Chem. 1, 109-132.

Ripamonti,U., Duneas, N., van den Heever, B., Bosch, C., and Crooks, J. (1997). Recombinant transforming growth factor-betal induces endochondral bone in the baboon and synergizes with recombinant osteogenic protein-1 (bone morphogenetic protein-7) to initiate rapid bone formation. J. Bone Miner. Res. 12, 1584-1595.

Ripamonti, U., Ferretti, C., and Heliotis, M. (2006). Soluble and insoluble signals and the induction of bone formation: Molecular therapeutics recapitulating development. J. Anat. 209, 447-468.

Ripamonti, U., Heliotis, M., and Ferretti, C. (2007). Bone morphogenetic proteins and the induction of bone formation: From laboratory to patients. Oral Maxillofac. Surg. Clin. North Am. 19(4), 575-589, vii.

Ripamonti, U., and Klar, R. (2010). Redundancy of Osteogenic Soluble Molecular Signals Initiating the Induction of Bone Formation. Science in Africa, Available at: http://www. scienceinafrica.co.za/2010/october/ bone_regeneration_full.htm

Ripamonti, U., Klar, R. M., Renton, L. F., and Ferretti, C. (2010). Synergistic induction of bone formation by hOP- 1 , hTGF- $\beta_{3}$ and inhibition by zoledronate in macroporous coralderived hydroxyapatites. Biomaterials 31, 6400-6410.

Ripamonti, U., Ramoshebi, L. N., Patton, J., Matsaba, T., Teare, J., and Renton, L. (2004). "Soluble signals and insoluble substrata: novel molecular cues instructing the induction of bone," in The Skeleton, eds E. J. Massaro, J. M. Rogers (Totowa: Human Press), 217-227.
Ripamonti, U., Ramoshebi, L. N., Teare, J., Renton, L., and Ferretti, C. (2008). The induction of endochondral bone formation by transforming growth factor- $\beta 3$ : experimental studies in the non-human primate Papio ursinus. J. Cell. Mol. Med. 12, 1029-1048.

Ripamonti, U., and Reddi, A. H. (1995) Bone morphogenetic proteins: applications in plastic and reconstructive surgery. Adv. Plast. Reconstr. Surg. 11, 47-73.

Ripamonti, U., and Roden, L. C. (2010). Induction of bone formation by transforming growth factor- $\beta_{2}$ in the non-human primate Papio ursinus and its modulation by skeletal muscle responding stem cells. Cell Prolif. 43, 207-218.

Ripamonti, U., van den Heever, B., Crooks, J., Tucker, M. M., Sampath, T. K., Rueger, D. C., and Reddi, A. H. (2000). Long-term evaluation of bone formation by osteogenic protein 1 in the baboon and relative efficacy of bone-derived bone morphogenetic proteins delivered by irradiated xenogeneic collagenous matrices. J. Bone Miner. Res. 15, 1798-1809.

Roberts, A. B., Sporn, M. B., Assoian, R. K., Smith, J. M., Roche, N. S., Wakefield, L. M., Heine, U. I., Liotta, L. A., Falanga, V., and Kehrl, J. H. (1986). Transforming growth factor type beta: rapid induction of fibrosis and angiogenesis in vivo and stimulation of collagen formation in vitro. Proc. Natl. Acad. Sci. U.S.A. 83, 4167-4171.

Saadeh, P. B., Mehrara, B. J., Steinbrech, D. S., Dudziak, M. E., Greenwald, J. A., Luchs, J. S., Spector, J. A., Ueno, H., Gittes, G. K., and Longaker, M. T. (1999). Transforming growth factorbetal modulates the expression of vascular endothelial growth factor by osteoblasts. Am. J. Physiol. 277(Pt 1), C628-C637.

Sampath, T. K., Muthukumaran, N., and Reddi, A. H. (1987). Isolation of osteogenin, an extracellular matrix-associated, bone-inductive protein, by heparin affinity chromatography. Proc. Natl. Acad. Sci. U.S.A. 84, 7109-7113.

Sampath, T. K., and Reddi, A. H. (1981). Dissociative extraction and reconstitution of extracellular matrix components involved in local bone differentiation. Proc. Natl. Acad. Sci. U.S.A. 78, 7599-7603.

Sampath, T. K., and Reddi, A. H. (1983). Homology of bone-inductive proteins from human, monkey, bovine, and rat extracellular matrix. Proc. Natl. Acad. Sci. U.S.A. 80, 6591-6595.

Sampath, T. K., and Reddi, A. H. (1984). Distribution of bone inductive proteins in mineralized and demineralized extracellular matrix. Biochem. Biophys. Res. Commun. 119, 949-954.

Senn, N. (1889). On the healing of aseptic bone cavities by implantation of antiseptic decalcified bone. Am. J. Med. Sci. 98, 219-243.

Spagnoli, A., O'Rear, L., Chandler, R. L. Granero-Molto, F., Mortlock, D. P., Gorska, A. E., Weis, J. A., Longobardi, L., Chytil, A., Shimer, K., and Moses, H. L. (2007). Tgf-beta signaling is essential for joint morphogenesis. $J$. Cell Biol. 177, 1105-1117.

Spemann, H. (1938). Embryonic Development and Induction. New Haven: Yale University Press.

Sun, P. D. (2003). Conserved in structure but diverse in recognition. Structure 11, 362-363.

Trueta, J. (1963). The role of the vessels in osteogenesis. J. Bone Joint Surg. 45B 402-418.

Urist, M. R. (1965). Bone: Formation by autoinduction. Science 150, 893-899.

Urist, M. R. (1968). The reality of a nebulous enigmatic myth. Clin. Orthop. Relat. Res. 59, 3-5.

Urist, M. R. (1994). “The search for and discovery of bone morphogenetic protein (BMP)," in Bone Grafts, Derivatives and Substitutes, eds $\mathrm{M}$. R. Urist, B. T. O'Connor, and R. G.
Burwell (London: Butterworths Heinemann), 316-362.

Urist, M. R., Dowell, T. A., Hay, P. H., and Strates, B. S. (1968). Inductive substrates for bone formation. Clin. Orthop. Relat. Res. 59, 59-96.

Urist, M. R., Silverman, B. F., Buring, K., Dubuc, F. L., and Rosenberg, J. M. (1967). The bone induction principle. Clin. Orthop. Relat. Res. 53, 243-283.

Urist, M. R., and Strates, B. S. (1971). Bone morphogenetic protein. J. Dent. Res. 50, 1392-1406.

von Haller, A. (1763). Experimentorum de ossium formatione. Opera minora, Vol. 2. Lausanne: Francisci Grasset, 400.

Wozney, J. M., Rosen, V., Celeste, A. J., Mitsock, L. M., Whitters, M. J., Kriz, R. W., Hewick, R. M., and Wang, E. A. (1988). Novel regulators of bone formation: molecular clones and activities. Science 242, 1528-1534.

Conflict of Interest Statement: The authors declare that the research was conducted in the absence of any commercial or financial relationships that could be construed as a potential conflict of interest.

Received: 24 August 2010; paper pending published: 07 September 2010; accepted: 08 October 2010; published online: 11 November 2010.

Citation: Ripamonti U and Klar RM (2010) Regenerative frontiers in craniofacial reconstruction: grand challenges and opportunities for the mammalian transforming growth factor- $\beta$ proteins. Front. Physio. 1:143. doi: 10.3389/fphys.2010.00143 This article was submitted to Frontiers in Craniofacial Biology, a specialty of Frontiers in Physiology.

Copyright (c) 2010 Ripamonti and Klar. This is an open-access article subject to an exclusive license agreement between the authors and the Frontiers Research Foundation, which permits unrestricted use, distribution, and reproduction in any medium, provided the original authors and source are credited. 